\title{
Planning and Implementation of Effective Collaboration in Construction Projects
}

Shelbourn, M, Dr.; Bouchlaghem, N.M, Professor; Anumba, C, Professor; Carrillo, P, Professor

Civil \& Building Engineering, Loughborough University, Loughborough, LE11 3TU. +44 (0) 1509 228745. m.a.shelbourn@lboro.ac.uk

\begin{abstract}
The 21st century is now seen as the time for the construction industry to embrace new ways of working if it is to continue to be competitive and meet the needs of its ever demanding clients. Collaborative working is considered by many to be essential if design and construction teams are to consider the whole lifecycle of the construction product.

Much of the recent work on collaborative working has focused on the delivery of technological solutions with a focus on web (extranets), CAD (visualisation), and knowledge management technologies. However, it is now recognised that good collaboration does not result from the implementation of information technology solutions alone. The organisational and people issues, which are not readily solved by pure technical systems, need to be resolved. However, approaches that exclusively focus on organisational and people issues will not reap the benefits derived from the use of technology, especially in the context of distributed teams which are the norm in construction.

Work currently being undertaken at Loughborough University aims to bring together the benefits enabled by the technology, with the organisational, and its people issues to provide a framework enabling high level strategic decisions to be made to implement effective collaboration. This paper reports on the initial stages of the project: the background to the project, the methodology used, and findings from the literature survey and the requirements capture survey conducted as part of the project.
\end{abstract}

Keywords: Collaborative working, methodology, needs and requirements capture, decision-making framework

\section{Introduction}

The new millennium has seen widespread recognition from research findings and the construction industry itself that the industry must embrace new ways of working if it is to remain competitive and meet the needs of its ever demanding clients. Inherent within this agenda of new ways of working is a move towards collaborative working (Latham, 1994; Egan, 1998) and its associated fields: concurrent engineering and lean production (Anumba et al., 2004). Collaborative working is essential if design and construction 
teams are to address the entire lifecycle of the construction product and take account of not only primary functionality but also productivity, buildability, serviceability and even recyclability (Kusiak \& Wang, 1993).

Much of the recent work on collaborative working has focused on the delivery of technological solutions (Kvan, 2000; Woo et al., 2001; Faniran et al. 2001) with a focus on the web, i.e. extranets, (Weippert et al. 2003; Nitithamyong \& Skibniewski, 2004; Sexton \& Barrett, 2004; Wilkinson, 2005), CAD (modelling and visualisation Kunz, 1999; Schwegler, 1999; Hew et al. 2001; Fulton, 2002; Edenius \& Borgerson, 2003; Smoliar, 2003; Waly \& Thabet, 2002; Zhu \& Issa, 2003; Donath et al. 2004; Hiremath \& Skibniewski, 2004;), and knowledge management technologies and systems (Rezgui et al., 1996; Lueg, 2001; Stewart et al., 2002; Stewart \& Mohamed, 2003; Asprey, 2004; Egbu, 2004; Kundu, 2004). However, it is now recognised that effective collaboration does not result from the implementation of information technology systems alone (Alvarez, 2001; Vakola \& Wilson, 2002; Ferneley et al., 2003). Therefore approaches that are purely based on information technology are bound to be less than successful, unless the organisational and people issues are considered as part of these implementations. On the other hand, approaches that exclusively focus on organisational and cultural issues do not reap the benefits derived from the use of technology, especially in the context of distributed teams (Grudin, 1994; Koschmann et al., 1996; Loosemore, 1998; Winograd, 1988; Eseryel et al., 2002; Baldwin, 2004), a delicate balance needs to be reached. Implementing ICT into a number of Architecture, Engineering and Construction (AEC) organisations crosses many cultural boundaries (Credé, 1997; Proctor \& Brown, 1997; Cheng et al., 2001). Managers of ICT implementations have to consider the barriers within the workplace that affect such introductions with a more strategic approach (Norton, 1995; Boddy \& Macbeth, 2000; Maguire, 2002). To make matters more difficult, many individuals are apprehensive when confronted with technological change through the introduction of new systems and technologies (Manthou et al., 2004; Erdogan et al., 2005), a need for a more strategically managed approach is sought, particularly for the construction sector.

The recognition of these issues has led to new research (Planning and Implementation of Effective Collaboration in Construction (PIECC)) being undertaken within the Civil and Building Engineering department at Loughborough University in the UK. The remainder of this paper describes the work leading towards the development of a prototype framework for the planning and implementation of effective collaboration in construction projects.

\section{PIECC Project background}

The construction industry was initially slow in the uptake of ICT to improve the performance of its projects. However, the last 5 years (2000-2005) has 
seen a marked increase in its use. The introduction of ICT has enabled the phenomenon of collaborative working to become part of the industry's every day practices. With the need to demonstrate the complexities of introducing collaborative working into projects already described as being important to the future success of the industry, the PIECC project aims to show how a more strategic approach to using ICT systems for collaboration on construction projects is achievable.

The project has a focus of supporting strategic decision-making by highlighting areas where collaborative working can be improved incorporating the organisational (business), project and users needs. The project will consider existing needs of the industry, other relevant requirements from participating organisations in the research throughout the phased iterations of the project. These needs are to be used as the basis for the development of a decision-making framework that facilitates the strategic planning and implementation of effective collaborative working policies and protocols. When carefully planned, and if based on informed decisions, it is believed that these policies and protocols will help organisations improve their collaborative working, achieve better benefits from it, and maximise the use of tools and techniques that are currently commercially available. Particular attention is given to the challenging requirements of distributed, heterogeneous and transient construction project teams together with the need to facilitate ubiquitous and serendipitous collaboration between team members across all stages of the project delivery process.

\subsection{Aim and objectives}

The main aim of the PIECC research is to develop a strategic decision making framework that will guide organisations in the planning for effective collaborative working practices and the implementation of suitable tools and techniques.

The associated objectives are to:

- review state of the art collaborative working with a focus on both practices and technologies;

- conduct a requirements capture survey for collaborative working in construction at the organisational and project user levels, and identify key areas for improvement in collaborative working;

The results of these objectives are the main focus of this paper. Other objectives include to:

- develop a framework for the planning and implementation of effective collaborative working taking into account both the organisational business processes and the project lifecycle processes; and 
- test and validate the framework within the construction project context.

To realise these objectives the PIECC project will follow a rigorous methodology incorporating many features of recognised requirements and software development lifecycle processes. The next section will describe the methodology used in the project.

\subsection{Project Methodology}

In order to achieve the objectives of the PIECC project, a number of different methods will be adopted. These are:

1. Use of published sources - through an extensive literature review to establish current 'state-of-the-art' practice on collaborative working - and associated areas of interest - both in construction and other industries.

2. Field studies - these will be conducted to establish current practice for collaborative working within collaborating organisations. These field studies will include questionnaires, semi-structured interviews and detailed case studies within the collaborating organisations (and identified key personnel from other organisations) to identify the requirements for collaborative working and the key issues to be considered at the organisational and project user levels.

3. Use a 'develop-test-refine' strategy (action research) - to improve the framework for effective collaboration. This is appropriate since the PIECC project is concerned with developing real-life solutions, and furthering the goals of 'science'. Thus, the initial framework will be developed, tested and refined to ensure that it is comprehensive and easy to use in construction projects.

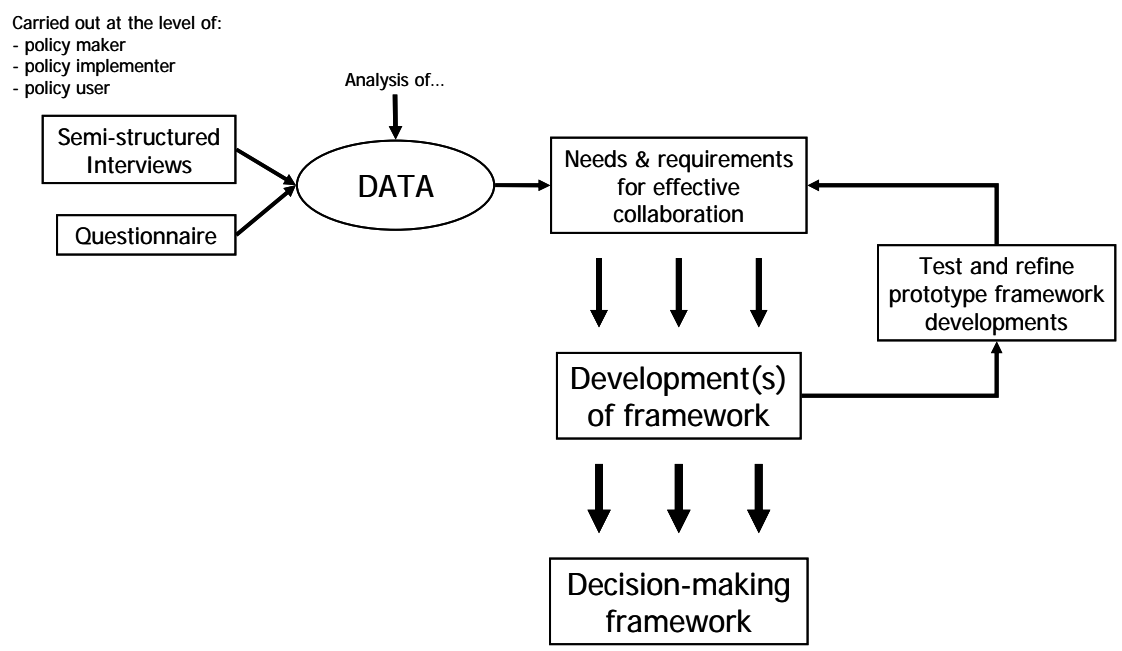

Figure 1: The PIECC projects' requirements capture methodology 
As we have already seen any developments made in the PIECC project should consider the organisational culture, project process and users' requirements for the implementation of collaborative tools and techniques. Thus, both 'soft' (i.e. the organisational and cultural aspects) and 'hard' (i.e. the technological) concepts and tools, will be adapted and combined to achieve the objectives of the research. The methodology for the PIECC project was chosen because of its relevance to the objectives of the research and current developments in the field of collaborative working in construction. Avison \& Fitzgerald (2003) provided an excellent means to compare different methodologies by using 7 similar elements to determine which methodology is the most appropriate for each context. Lessons from past research initiatives also suggest that the combined approach of 'soft' and 'hard' is the most sensible approach to be adopted (Tiwana, 2000).

Requirements analysis centres on getting all users to identify needs, problems and expected benefits. The main deliverables are a statement of the functional requirement (sometimes referred to as the user specification or the requirements specification), and at least the outline of an acceptance test plan which will stand as the main reference point during the later stage of acceptance testing.

Historically, the process of requirements analysis has been ill defined, and fraught with difficulty and misunderstanding (Robertson \& Robertson, 1999 pp.4-5). Nowadays, it is subjected to the discipline of structured methods and is becoming better understood. It is very important to the success of the PIECC project, and it has been seen as the area of greatest investment of time and effort.

\section{State of the Art}

As with many research and development activities the PIECC project began with a comprehensive review of existing data and information. The literature survey (see Shelbourn et al., 2005) centred around collaborative working, and a number of associated areas.

The survey was conducted as a desktop study, and determined through intensive data gathering and analysis activities from the Internet, published and case study material from many different sources, to determine the current state-of-the-art of collaborative working in the construction sector. The literature review included other specific subjects: collaboration technologies (Koseoglu et al., 2005) - including GRID technologies; and the change management implications of implementing and using new technologies for construction organisations (Erdogan et al., 2005) as these are seen as important aspects to the success of collaborative working.

The remainder of this section describes the major findings from the comprehensive literature survey conducted during the first stages of the PIECC project. The survey centred on the theme of collaborative working and its associated subjects. To begin the survey the research team aimed to 
define "collaborative working". The results show that there were many definitions of collaborative working in the literature. Some incorporated the word "concurrent" in terms of the approach and activity, and "collaborative" in terms of ownership (Moore, 2000). Other definitions were provided by (Clemmet, 1997; Kvan, 2000; Robillard \& Robillard, 2000).

From the reading of these descriptions it was found to be easier to describe the different forms that collaboration can take. In their model Anumba et al., (2002) describes four modes of collaboration, and typical forms of use in the four areas are described by Attaran \& Attaran, (2002). These descriptions are combined and shown in Figure 2.

\begin{tabular}{|c|c|c|c|c|c|}
\hline & Same time & Different time & & Same time & Different time \\
\hline Same place & $\begin{array}{l}\text { Face-to-face } \\
\text { collaboration }\end{array}$ & $\begin{array}{l}\text { Asynchronous } \\
\text { collaboration }\end{array}$ & Same place & $\begin{array}{l}\text { Information centres } \\
\text { Team rooms } \\
\text { Task delegation }\end{array}$ & $\begin{array}{c}\text { Electronic mail } \\
\text { Computer conferencing } \\
\text { Data sharing }\end{array}$ \\
\hline Different place & $\begin{array}{l}\text { Synchronous } \\
\text { Distributed } \\
\text { collaboration }\end{array}$ & $\begin{array}{l}\text { Asynchronous } \\
\text { Distributed } \\
\text { collaboration }\end{array}$ & Different place & $\begin{array}{l}\text { Teleconferencing } \\
\text { Videoconferencing } \\
\text { Conference publishing }\end{array}$ & $\begin{array}{l}\text { Electronic meeting rooms } \\
\text { Design conferences } \\
\text { Project management }\end{array}$ \\
\hline
\end{tabular}

Figure 2: Forms and types of use of collaboration

From the literature survey the PIECC project found that in much of the research 'collaborative working' was described in a number of different contexts:

- general terms - the use of technology to enable project stakeholders to exchange information and communicate easier on projects (Jasnoch \& Haas, 1996; Faraj et al., 2000; Dustdar \& Gall, 2003; Li \& Fou et al., 2004; Li \& Shao et al., 2004);

- for design - using tools and technologies to exchange design ideas and iterations quicker and to discuss the design in real-time. These tools also provide the design team with an audit trail for managing the design process. (Brusasco et al., 2000; Hale \& Marvis, 2000; Peña-Mora et al., 2000; Wang et al., 2002; Barbosa et al., 2003; Lau et al., 2003; van Leeuwen, 2003; Chim et al., 2004);

- for management of the construction project - tools that provide all stakeholders (dependent on their user privileges) access to the most up to date information. Tools also provide a detailed overview of the project status allowing management to track progress etc. (Attaran \& Attaran, 2002; Andersen et al., 2003);

- visualisation - allows stakeholders to view detailed and often complicated sets of information in a format that is easily recognisable. Particularly give clients and end users the ability to see the finished facility before onsite activities begin. This means that changes (from the client or conflict resolution) can be made earlier 
in the process (Caneparo, 2001; Sriprasert \& Dawood, 2003; Whyte, 2003) and

- simulation - similar to visualisation but concentrates on providing stakeholders the experience of using the building before onsite activities begin. This means that potential problems with the use of the finished facility can be realised at the design phase (Bossak, 1998; Augenbroe, 2002).

In many cases the reported research provides case study material describing the different uses of collaboration in different contexts. Specific examples from a number of industries include:

- $\quad$ the construction industry (Willaert et al., 1998; Bresnen \& Marshall, 2000; Wilkinson, 2005);

- $\quad$ the healthcare sector (Conner \& Finnemore, 2003);

- the automotive industry (Beecham \& Cordey-Hayes, 1997; May \& Carter, 2001);

- global manufacturing (Abdalla, 1999); and

- $\quad$ virtual learning in groups (Mcfadzean \& McKenzie, 2001).

\subsection{Key areas for Collaboration}

The literature survey concluded that for an organisation (or organisational unit) to 'effectively collaborate' there must be a balanced harmonisation of three key strategies: business, people, and technology.

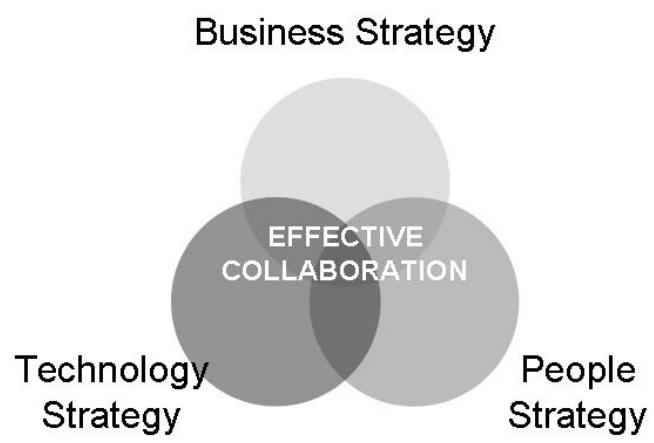

Figure 3: Key areas for effective collaboration

Usually collaboration enables participants to build capacity to complete a set of tasks that one sole organisation would find difficult to achieve. The collaboration eliminates fragmentation, duplication and distrust. This is achieved by intelligently using available resources wisely, sharing the multiple project risk factors across multiple domains, and enhancing staff and organisational motivation. This can only be achieved 'effectively' by bringing together and aligning the three strategic areas of: business, people and technology (see Figure 3). 
There are many factors that are likely to influence the success or failure of working collaboratively. It is important to realise that no two collaborations will progress in exactly the same way or within the same time frame, a factor that may prove difficult to build into the PIECC projects decisionmaking framework. The PIECC results must enable each collaboration to find a way to proceed that is consistent with its unique circumstances and composition. Important to this are 6 key areas recognised as being critical aspects of each of the three strategies shown in Figure 3.

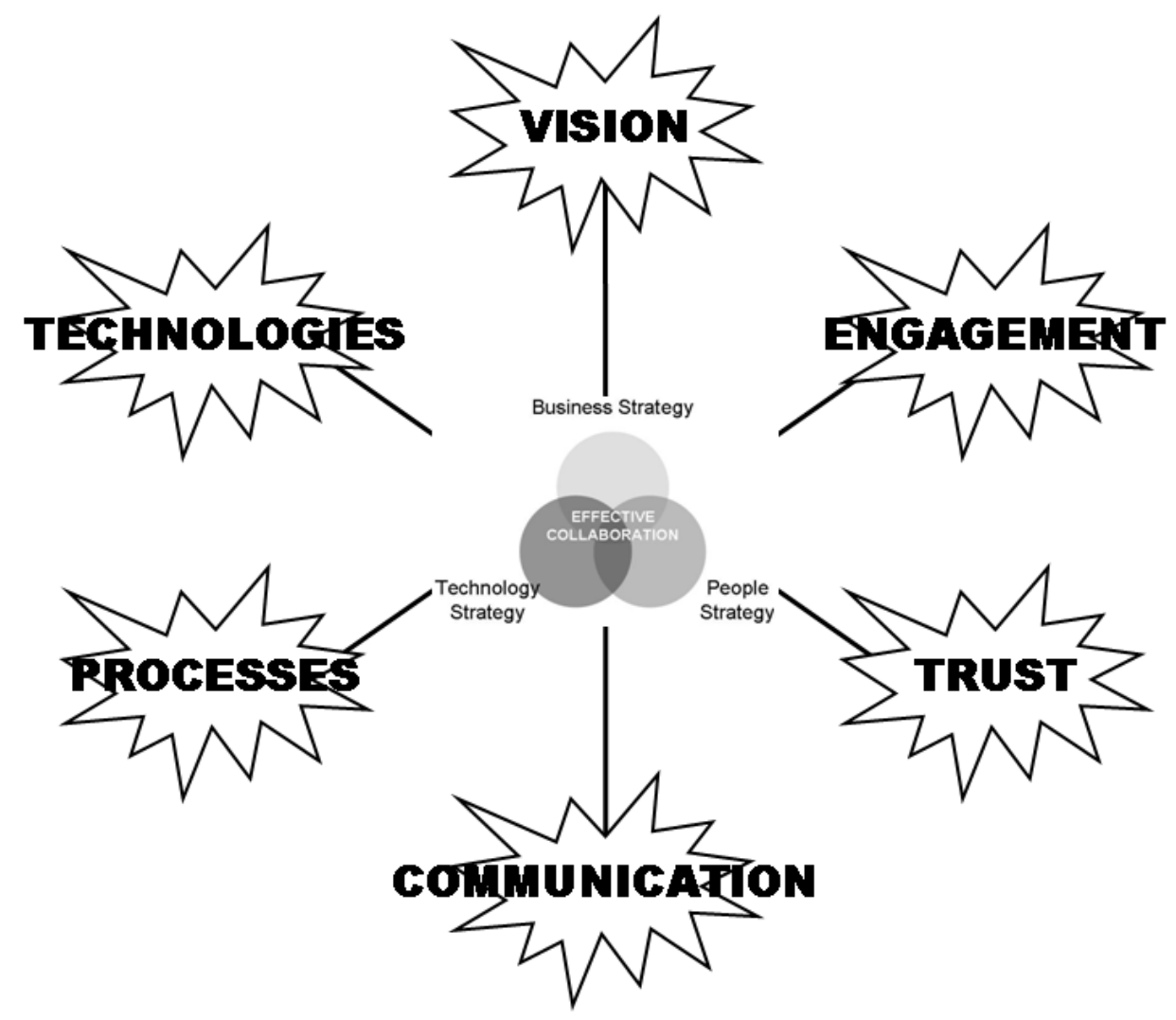

Figure 4: Areas to be addressed in the strategies to enable effective collaboration

The areas are:

- Vision - all members of the collaboration agree on the collaborations aims and objectives;

- (Stakeholder) Engagement - collaboration leaders need to ensure that all key participants are consulted as to the practices to be employed during the collaboration;

- Trust - time and resources are needed to enable all participants to build trusting relationships;

- Communication - a common means of communication is decided by all key participants in the collaboration; 
- Processes - both business and project, that describe to all key participants how the collaboration is to work on a day-to-day basis;

- Technologies - an agreement on those to be used to ensure the collaboration is easily implemented and maintained.

All six areas need to be addressed in the three strategic areas described to have "effective collaboration" in the organisation/project context. However, the strategies may be different depending on the context of the proposed collaboration. Differences exist in effective collaboration at the project and organisational level.

Perhaps the most important overarching aspect of effective collaboration is that working collaboratively often means 'new ways of working' for many/all of the participants involved in the collaboration. Effective collaboration is only achievable through the innovative design and development of a more balanced 'collaboration strategy', that does not rely solely on sophisticated information and communication technologies. As yet there is little evidence of such a 'strategy' existing that prescribes to managers effective ways of implementing and managing collaborative projects/environments. A projected result of the PIECC project is to define what this strategy should consist of to take advantage of the benefits provided by a more targeted use of ICT that is better aligned to an organisations people and business processes.

Initial findings from the PIECC project suggest that it is essential to allow stakeholders to take the necessary time from routine responsibilities to meet and interact with one another so that trust and respect on an individual level can be generated. Personal interactions across the collaborating stakeholder organisations that are attempting to nurture trusting relationships will encounter the growing pains naturally associated with systemic change associated with the new ways of working. It is worthy of note, that change (i.e. change management principles) begins with individuals, not institutions.

\section{Field Studies}

In many development methodologies/lifecycles the importance of the field studies is critical to the success of the developed method, tool, software, etc. (Robertson \& Robertson, 1999). The PIECC project also recognises the importance of this aspect of the project. As part of the requirements capture process it was decided, by the research team and the industrial partners, that a combination of semi-structured interviews, workshops and questionnaires would be used to gather the needs and requirements for the PIECC project. Where each method was used - and how it was used - was discussed with each partner, meaning that the methods used for each organisation were slightly different. The key aspects of the field studies are described in the sections below. 


\subsection{Questionnaire Design}

There are many useful texts and guides to designing questionnaires (Bloom and Fischer, 1982; Kidder and Judd, 1986; Newell, 1993; and Burns, 2000) to list a few. For the purposes of the PIECC project a combination of best practices from each text, i.e. question design, phraseology and layout, length of questionnaire etc, used to design the questionnaire. The research team felt that this approach would yield a larger response from those persons that the questionnaire was sent out too.

To gain balanced information from all members of each of the participating organisations, two questionnaires were proposed to be developed for the project. One of these was to be targeted towards senior personnel in the organisation, and the other aimed at the project worker level. After careful consideration and input from the industrial partners, through a number of iterations of each questionnaire, it was felt that a single questionnaire designed to cover the pertinent issues would suffice.

Different versions of the questionnaire went through a rigorous development process, with the final version being used to seek the views from individuals in the industrial partners organisations represented in the PIECC project. The overall view of the questionnaire was positive, and that it covered the relevant issues and would be a useful tool for the gathering of the needs and requirements sought by the research team.

The questionnaire was split into different sections reflecting the types of information the research team required. The first three sections sought data on the individual, their organisation and different strategies (business and IT) for their organisations. Section four - sought opinions on collaborative working in general, before concentrating on questions seeking clarification on the importance of the "6 key areas of collaboration" found to be critical in the results of the literature survey, explained later in the paper.

The main results from the questionnaire are described in the next section.

\subsection{Results from the questionnaires}

The PIECC project designed a questionnaire to determine the key aspects to consider in planning and implementing collaboration effectively in construction projects. The questionnaire was sent out to partners, contacts and posted on the project website.

In total, six interviews and sixteen questionnaires were completed in the requirements capture stage of the project. The questionnaire was sent out to approximately forty people, aimed at the construction project worker (the day to day management of projects), giving a response rate of $40 \%$. The interviews were conducted at a more senior management level. The data collected from these interviews and questionnaires were analysed and synthesised, and used to determine the key aspects of collaboration. These key aspects were used to inform the future developments of the project. 
One of the key questions asked was:

4.1 Please rank the following three areas in order of importance to effective collaboration

\begin{tabular}{l||c|c|c|c} 
& Essential & $\begin{array}{c}\text { Very } \\
\text { important }\end{array}$ & Important & $\begin{array}{c}\text { Not } \\
\text { important }\end{array}$ \\
\hline \hline Business Processes \& Procedures & {$[\ldots \ldots]$} & {$[\ldots \ldots]$} & {$[\ldots \ldots]$} & {$[\ldots \ldots]$.} \\
$\begin{array}{l}\text { Technology } \\
\text { People }\end{array}$ & {$[\ldots \ldots]$.} & {$[\ldots \ldots]$.} & {$[\ldots \ldots]$} & {$[\ldots \ldots]$.} \\
& {$[\ldots \ldots]$.} & {$[\ldots \ldots]$.} & {$[\ldots \ldots]$} & {$[\ldots \ldots]$.}
\end{tabular}

The results of this question are depicted in Figure 5. The results show that respondents believe that 'people' are the most important aspect of a successful collaboration. This is followed by 'business processes \& procedures' and 'technology' aspects respectively. This means that the focus of any developments of the PIECC project should concentrate on the people and process aspects of collaborative working. The results compliment current thinking of many in the construction industry, in that any resources for technology implementations should be split: $40 \%$ people, $40 \%$ process, and $20 \%$ technology (Wilkinson, 2005). However, no study of collaborative working can exclude the technology, indeed, it is a fundamental aspect of it. Initial developments in the PIECC project have highlighted tools and techniques that allow technology to be used in collaborative working, and show how these technologies may be used in a supporting role of the processes and people aspects.

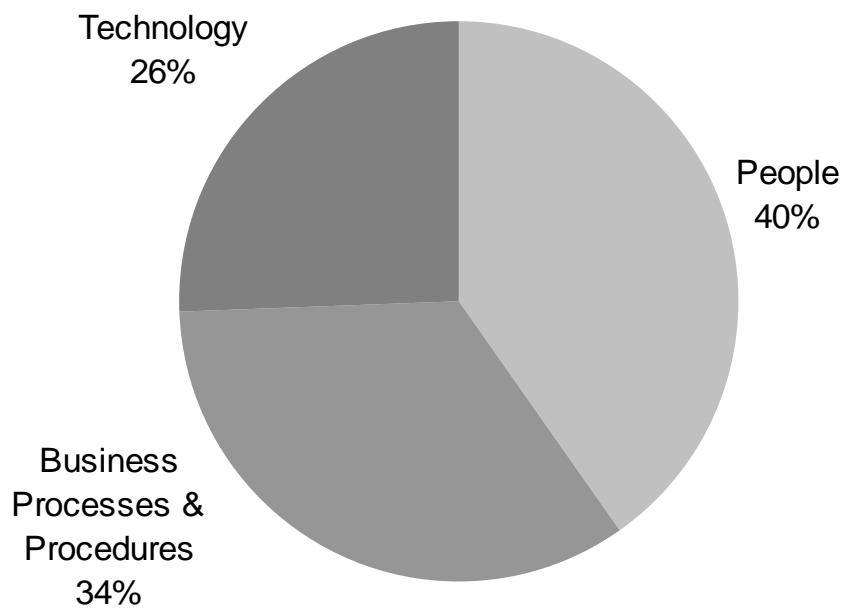

Figure 5: The importance of the 3 key strategies for effective collaboration

Another question asked was designed to determine the importance of the 6 key areas for effective collaboration (shown in Figure 4), the question was: 
4.2 Research has shown that there are 6 critical success areas to ensure effective collaboration. Please rank the importance of these - ( 1 is highest, 6 the least, you may only use each number once).
A shared vision
Engagement of stakeholders
Building trusting relationships
Good communication
Clearly defined processes
Well integrated technologies

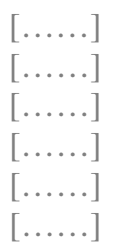

The users were asked to rank these success areas between 1 and 6, 1 being the most important down to 6 being the least. The results for question 4.2 are shown in Figure 6.

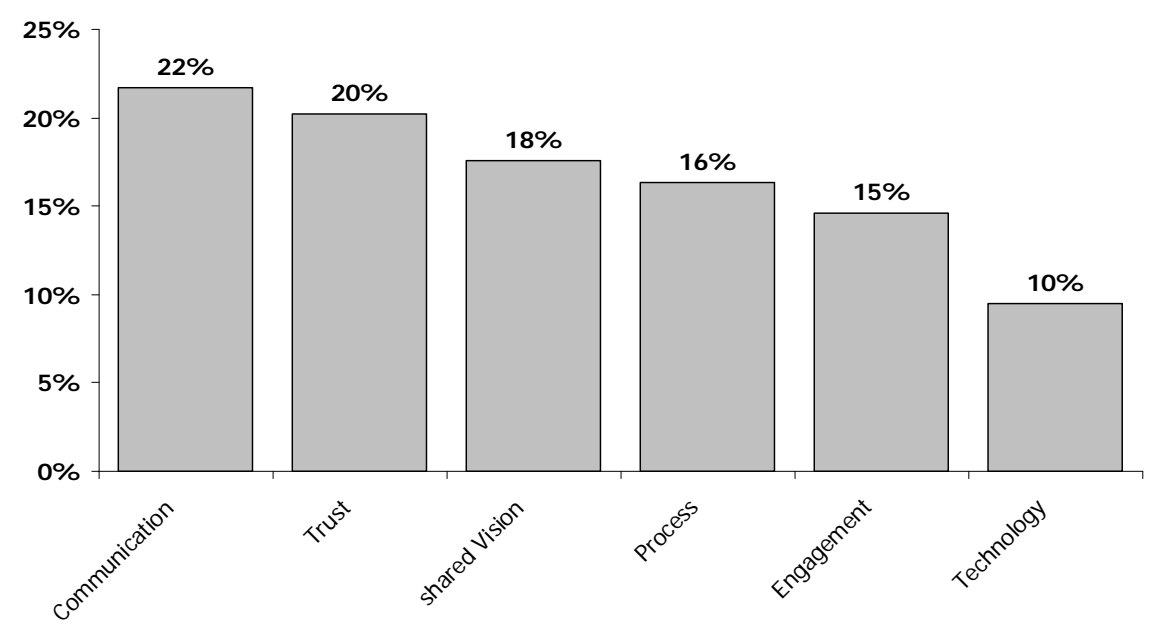

Figure 6: Graphical representation of the results to Question 4.2

The results show the importance of communication in working collaboratively. However, there is no strong finding that any one of the six aspects is the most important factor. Developments within the PIECC project have to reflect this and make sure that all 6 key areas are addressed in the different strategies required for effective collaboration.

\subsubsection{Other Key Findings from the questionnaire}

Of the participants who have completed the questionnaire $81 \%$ of them have been part of a team who have been responsible for the planning and implementation of collaborative environments/projects. In this $81 \%, 77 \%$ of environments/projects had protocols available that described processes to aid in the planning and implementation of the project/environment, with $66 \%$ of participants finding such protocols useful. When asked “...do you think that such a protocol would aid the collaboration planning and 
implementation process..." $66 \%$ of respondents said they would, $7 \%$ said that they would not, and $27 \%$ did not know.

When the respondents were asked what are the essential contents of such a protocol, they responded as Figure 7 graphically shows. The figure tells us that all the aspects listed are important to the development of a decisionmaking framework that enables the effective planning and implementation of collaborative working in the construction sector. However, there are a number of aspects - communication procedures; interoperability standards; building trust; a common vision and priorities; and engaging key stakeholders - that really make a significant contribution to the success of working collaboratively. It is the intention of the PIECC project to provide a framework that brings together these aspects in future developments.

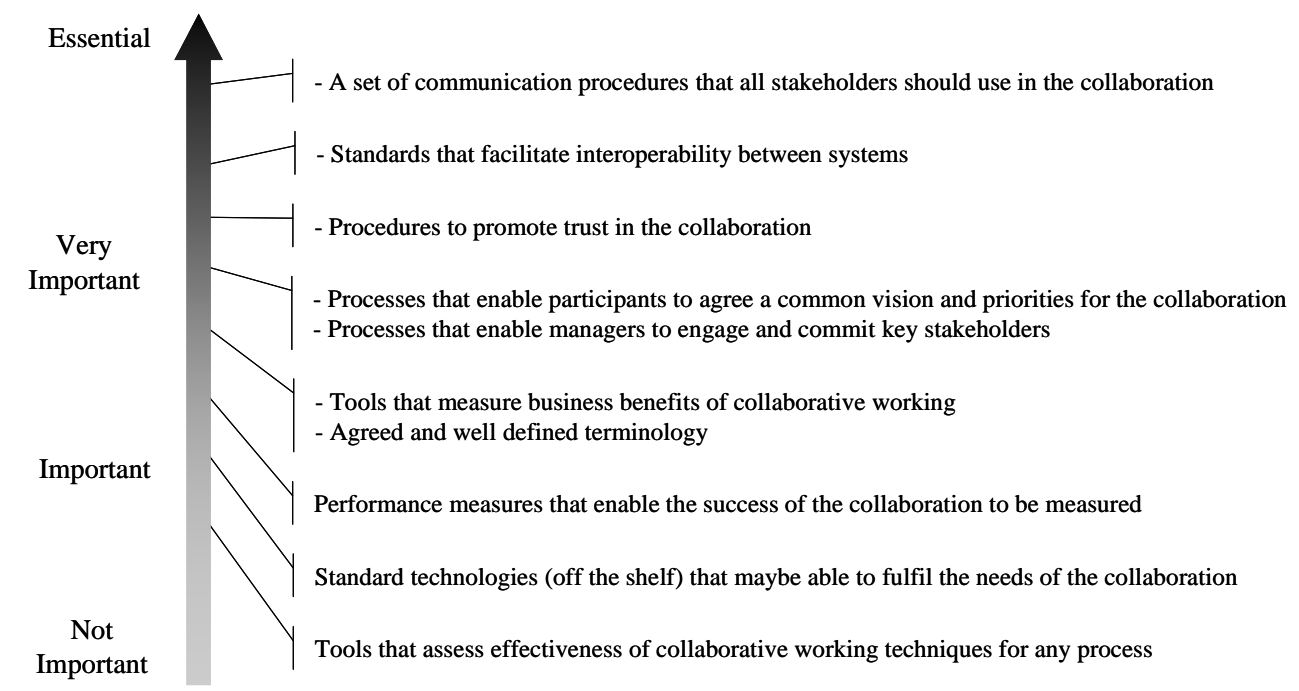

Figure 7: Importance of aspects of a collaborative working protocol

The PIECC project took the opportunity to determine which of the commercially available collaboration tools on the market were currently being used in projects.

Figure 8 summarises these results. At this time 'Asite' is the most commonly used with 'BIW' (Building Information Warehouse, and '4projects' the next popular. All of these systems provide a construction project with software that enables project information to be uploaded, stored and distributed between the project stakeholders. They all provide essentially the same service, the only real differences being how each tool/system portrays the information it contains, and how each individual user interacts with that tool/system. 


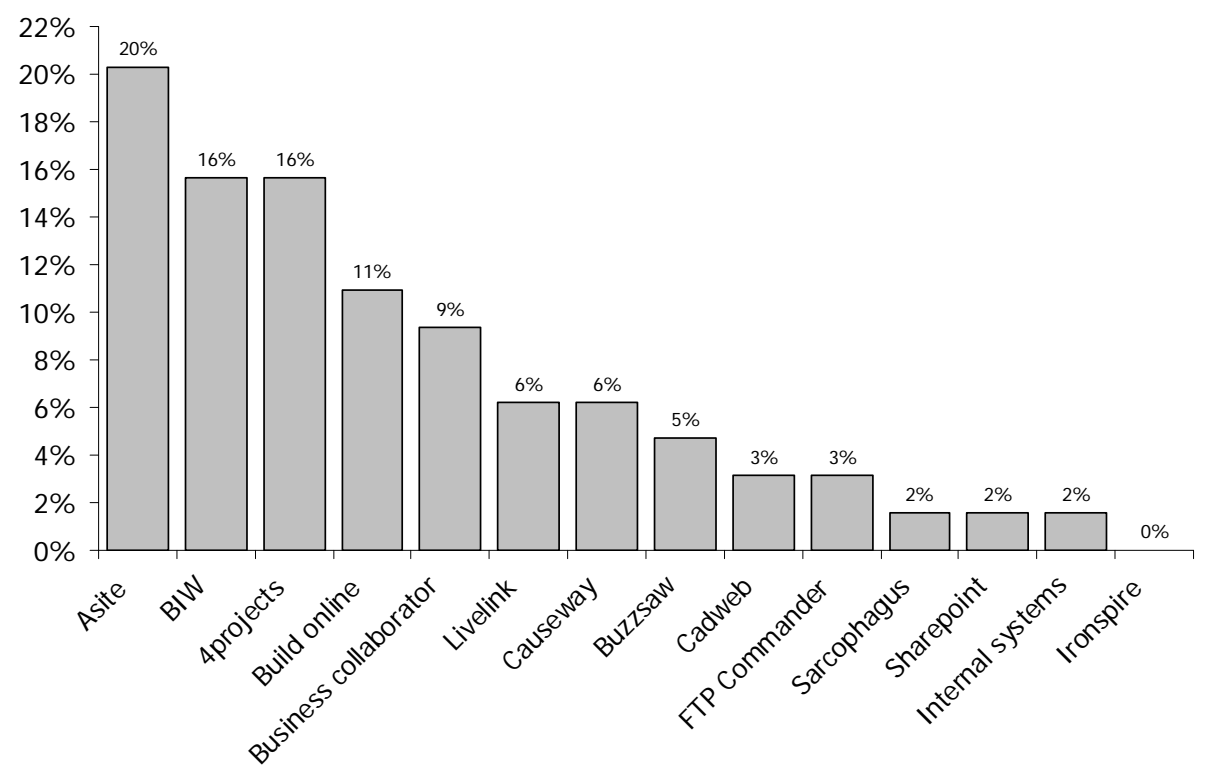

Figure 8: Results of the use of different collaboration software

The questionnaire also asked the respondents what were the key aspects for collaboration software/systems. Figure 9 shows the results of this question.

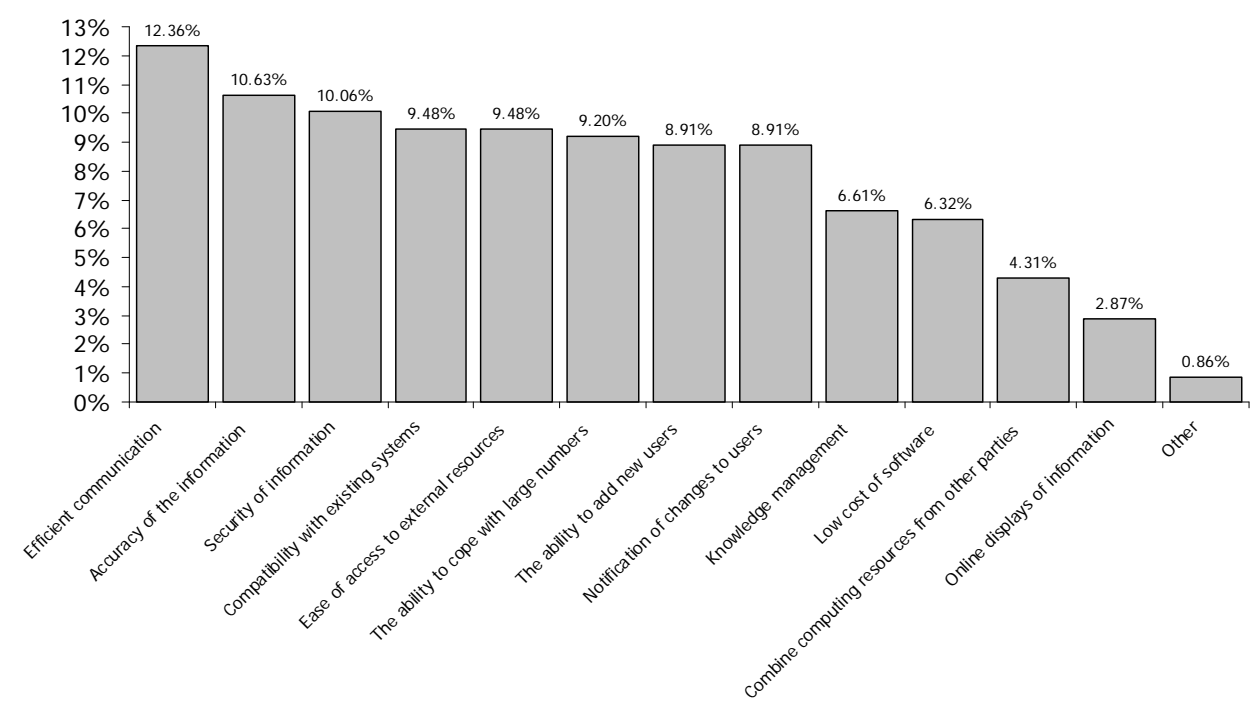

Figure 9:The most important aspects of collaboration software

Although the development of software to enable effective collaboration is beyond the scope of the PIECC project it is important for the project tbeam 
to realise what are the important aspects of collaboration software, and build procedures into the framework that can be addressed by this software.

As well as completing the project questionnaire, pertinent questions were also asked in a number of semi-structured interviews to determine the needs and wants of personnel working in the construction industry. The method used and the results elicited from these interviews are described in the next section.

\subsection{Interviews}

The methodology for the capture of the needs and requirements (Figure 1) shows that a number of interviews were needed to gain the views of prominent players within the construction industry. The PIECC project used the semi-structured interview approach with senior managers/directors of major organisations, and project workers 'at the coal face' within the industry to achieve this.

The semi-structured interviews enabled the research team to develop a fairly open framework - adapted from the project questionnaire - that allowed for focused, conversational, two-way communication between the participants and the research team. The interviews allowed for more general questions to be used enabling the interviewer and the person being interviewed the flexibility to probe for details and/or to discuss the more appropriate topics relating to effective collaboration working issues. The results of these interviews are discussed in the " 4.4 Results from interviews" section below. The data collected from a range of techniques were verified with the participating organisations. The analysis provided the project with data to aid in the seeking of the needs and requirements for the development of a framework to enable effective collaboration in the construction sector.

The next section describes the results from the interviews and how these results were combined with the questionnaire results to determine the key needs and requirements for effective collaboration in the construction sector.

\subsection{Results from interviews}

As part of the project methodology a number of semi-structured face-to-face interviews were undertaken. Six recognised leaders of project collaborations in their respective organisations were chosen. The questions developed in the questionnaire were used as a base for the interviews. Each interview lasted between 60-90 minutes, and were not recorded. The results from the interviews complemented the results from the questionnaires. The issues raised can be attributed to areas of questions developed in the questionnaire. The following sections describe the interview findings. 


\subsubsection{Ease of use}

The respondents describe how "...many of the different collaboration software/systems that are available, have failed to address the familiarity of the tools used by participants in the collaboration..." as being a key issue for any future developments. Many lessons can be learnt from the 'Knowledge Management' domain in this respect. It is desirable to have some form of "help template" that is available to new users of the tools. Once they are familiar with the tool, then this template disappears and does not bother the user in the future, unless requested by them. Respondents commented on "...being frustrated with collaboration software...". Evidence is needed to show those that are frustrated need not be in the future, through the benefits afforded by initiatives such as PIECC. This evidence needs to be well supported with "industry support and suitable examples", and will be a key challenge for future work of the project.

Respondents also voiced concerns about collaboration software adding an extra layer to communication amongst participants in a project. This has often led to a single person being employed to interface between the collaboration software and the design team to prevent time being added to the design phase of a project.

One issue that is beyond the scope of this project, but has been raised by a number of the interviewees concerns the "ease of use of interfaces". Respondents felt that the intuitiveness of these at this time means that much training is needed before project participants can use them. The actual layout of them also proves difficult with some respondents commenting that “...there seems to be a lack of thinking by designers...”. Respondents would like to see standard and simpler interfaces designed for project collaboration software.

\subsubsection{Changing the project culture}

Any framework developed must address the issue of "conflict resolution" and the "blame culture" of the industry, i.e. it must prevent the "shutters coming down" as soon as any problems are identified in the workings of the collaborative environment/project. Information is needed to enable conflicts to be managed, and reduced throughout the duration of the collaborative project/environment. The industry needs to work towards a culture of "...identification of the problem - address it - solve it - and then move on..." rather than try and apportion blame for the problem and its associated ramifications - often costly legal proceedings.

Any developments made within research projects such as PIECC should be aiming to build upon initiatives such as the AVANTI programme (Avanti, 2006). The AVANTI programme was a two year initiative sponsored by the Department of Trade and Industry (DTI) - a part of the UK Government. It was led by a group of well-respected and influential construction people with an aim of developing “...an approach to collaborative working that 
enables construction project partners to work together effectively." The approach focuses on people, processes, and mobilising existing technologies, to agree upon working practices and procedures through the use of a number of developed toolkits. More information maybe found at http://www.avanti-construction.org. The results from the Avanti programme have complemented and influenced the work being undertaken in the PIECC project. Nearly all interview participants stressed the importance of the work currently being undertaken by AVANTI and see the PIECC project as adding to this work.

A small number of respondents queried the inclusion of vision and engagement (of stakeholders) as part of a framework for effective collaborative working. Their view was that if people are already sat around 'the table' then the vision and stakeholders are already chosen. Why waste time choosing them? Why not get on with the project with who you have? There is a recognition from the industry that these issues exist and may need addressing, but they are not as significant as the processes and technology to be used in the project, and it is on these that participants should concentrate their efforts.

\subsubsection{New forms of contract}

It is worthy of note that although many of the respondents described their organisations as working towards collaborative and strategic partnerships with their supply chains, there is actually little evidence of this actually being achieved. There are many reasons for this but one that was continually voiced in the interviews was a lack of contract that takes into account the new ways of working that working collaboratively now entails. There is a need for contracts that are different from traditional construction projects, in that they take into account long term relationships with clients and other project stakeholders, and should be built upon the principles laid down in the Latham report. Research in the PIECC project has highlighted a number of initiatives that aim to provide such contracts: Collaborating for the Built Environment (BE) and their 'collaborative contract' (see http://www.bcc.beonline.co.uk/); the 'New Engineering Contract' and 'PPC 2000/3' are all seeking to address this need. However, take-up and evidence of successful use are still needed before widespread use in the industry is achieved. Other contractual aspects that need addressing include: payment mechanisms - with traditional methods not being appropriate for collaborative working.

\subsection{Summary of needs and requirements for effective collaboration}

This section brings together information from the results of the conducted interviews and questionnaires to provide a summary of what the industry's 
requirements are for the planning and implementation of effective collaboration in projects.

The interviews and questionnaires have enabled a clear set of needs and requirements to be determined for the PIECC project. The list below summarise the comments and questions provided by the industry (represented through the project partners and other key personnel) for a framework to plan and implement effective collaboration. The requirements are categorised under 6 headings. These headings and their listed requirements provide an overview of what is required to enable effective collaboration to be planned and implemented in a more productive manner in the future. The industry needs are:...

\section{Model}

- “...a recognisable model for collaborative working does not exist at this time - it needs developing to enable a move forward..."

- "...must build upon work being done in other aspects of collaborative working - the AVANTI programme for example..."

\section{Process}

- “...processes that enable participants to agree a common vision and priorities for the collaboration - a route map for how the project is going to proceed, and must include suitable time for review of progress against vision and priorities..."

- “...procedures to promote trust in the collaboration - a key person needs to be in charge, they provide leadership, leading (hopefully) to better performance of the team, to build trust within the team..."

- "... a set of communication procedures that all stakeholders should use in the collaboration..."

\section{Standards}

- “...standards that facilitate interoperability between different software and systems - we are fed up with learning a new system for every new project!!...”

- “...suitable (and appropriate) help templates/screens for users to familiarise themselves with the software tools. They are removed when a level of competence is reached..."

\section{Good Practice}

- "...examples of good practice/case study material that shows tangible business benefits of collaborative working..."

- "...evidence of good practice of collaborative working to be

\section{Design} published to alleviate frustration of the industry..."

- "...intuitive interface design of software to reduce the requirement for training of new members of a collaborative project/environment..." 


\section{Legal aspects}

- “...clarification of professional liability of information generated. Who is responsible for the information generated and its trustworthiness? A right balance between the technology and professional liability is the issue to building trust..."

Armed with these key needs and requirements the PIECC project is able to move to the next stage, the development of a prototype decision making framework. Initial work has begun on this and is described in the next section.

\section{Further work}

Having determined the needs and requirements for a decision making framework for the planning and implementation of effective collaboration the next challenge for the research team is to transform these needs and requirements into something that the industry can readily use. Provisional explorations with selected parties has produced the model in Figure 10. It is felt that these four aspects should all be covered within any developments made during the project.

The adding of material to these four ideas, and the development of the prototype decision making framework is the focus of the next stage of the project. Once a prototype has been finalised it will be tested in the organisational and project context in PIECC partner organisations. Feedback and comment will then inform any new aspects that may need to added to the framework, before being tested in other organisations. This whole process is scheduled to last 12 months.

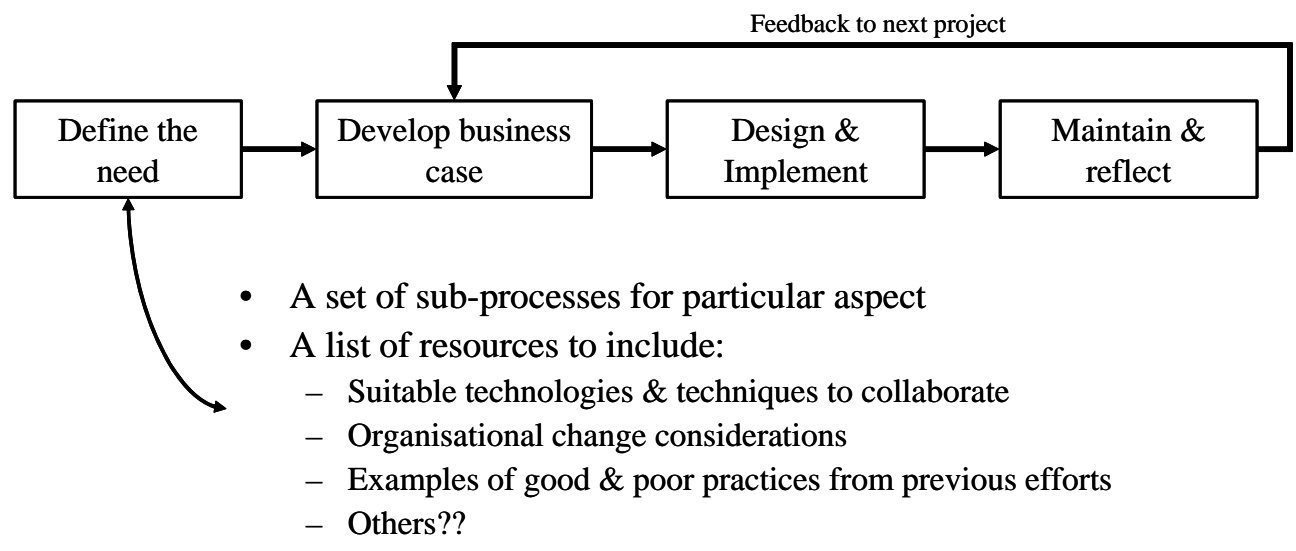

Figure 10: Provisional ideas for the decision-making framework 


\section{Conclusions}

The planning and implementing of 'effective' collaboration is still in its early stages of widespread adoption within the construction industry. This paper has described the particular issues faced in the adoption of collaboration in construction projects. It has shown that for effective collaboration there needs to be a recognition of the 'softer' issues as well as the technological ones. To this end the paper has shown that collaboration requires three different strategies to come together to enable its success: technology, business and people (see Figure 3). Within each of the three strategies there are 6 key factors that need to be considered in the development of the strategy. These have been described in the paper and can be seen in Figure 4.

The paper has described in some detail current research being undertaken by the authors to provide a decision making methodology/framework to aid in the development of these strategies. The work that has been completed within the PIECC project has been described. This work includes a comprehensive literature survey, the design and development of a questionnaire - sent to relevant parties - as well as being used as a basis for the carrying out of a number of semi-structured interviews. The results of these have been thoroughly described within the paper. Future work and initial thoughts on the prototype have also been described.

\section{References}

Abdalla, H.S. 1999 Concurrent engineering for global manufacturing. International Journal of Production Economics, 60-61, pp.251-260. Elsevier Science

Alvarez, R. 2001 "It was a great system" Face work and discursive construction of technology during information systems development. Information, Technology \& People. 14(4), pp.385-405. MCB University Press

Andersen, J.L., Christensen, K. and Howard, R.W. 2003 Project management with a project web. ITcon, 8, pp.29-41. Available from: http://www.itcon.org. Last visited $26^{\text {th }}$ January 2005

Anumba, C.J., Ugwu, O.O., Newham, L. and Thorpe, A. 2002 Collaborative design of structures using intelligent agents. Automation in Construction. 11(1), pp.89-103. Elsevier Science

Anumba, C., Aziz, Z. and Ruikar, D. 2004 Enabling technologies for next-generation collaboration systems, Proceedings of the INCITE 2004 Conference Designing, Managing and Supporting Construction Projects through Innovation and IT Solutions. Langkawi, Malaysia, 18-21 February 2004, pp.85-96;

Asprey, L. 2004 Information strategies: are we aligning the business case with enterprise planning? Records Management Journal. 14(1), pp.7-13. Emerald Group Publishing Limited, ISSN 0956-5698

Attaran, M., and Attaran, S. 2002 Collaborative Computing Technology: The Hot New Managing Tool, Team Performance Management, 8(1/2), pp.13-20

Avanti 2006 see http://www.avanti-construction.org for more details

Avison, D. and Fitzgerald, G. 2003 Information Systems Development: Methodologies, Techniques and Tools. $3^{\text {rd }}$ edition. McGraw Hill Education. ISBN 0-07-709626-6

Augenbroe, G. 2002 Trends in building simulation. Building and Environment, 37, pp.891-902. Pergamon, Elsevier Science 
Baldwin, A. 2004 Overcoming the Barriers to the Successful Introduction of Collaborative Technologies in Construction, Proceedings of the INCITE 2004 Conference Designing, Managing and Supporting Construction Projects through Innovation and IT Solutions. Langkawi, Malaysia, 18-21 February 2004, pp.319-326;

Barbosa, C.A.M., Feijó, B., Dreux, M., Melo, R. and Sérgio, S. 2003 Distributed object model for collaborative CAD environments based on design history. Advances in Engineering Software, 34, pp. 621-631. Elsevier Science

Beecham, M.A. and Cordey-Hayes, M. 1997 Partnering and knowledge transfer in the UK motor industry. Technovation, 18(3), pp.191-205. Pergamon, Elsevier Science

Bloom, M. and Fischer, J. 1982 Evaluating Practice: Guidelines for the Accountable Professional, Prentice Hall, New Jersey.

Boddy, D. and Macbeth, D. 2000 Prescriptions for managing change: a survey of their effects in projects to implement collaborative working between organisations. International Journal of Project Management, 18(5), pp.297-306. Elsevier Science;

Bossak, M.A. 1998 Simulation based design. Journal of Materials Processing Technology, 76(1), pp.8-11. Elsevier Science

Bresnen, M. and Marshall, N. 2000 Building partnerships: case studies of clientcontractor collaboration in the UK construction industry. Construction Management and Economics. 18, pp.819-832. ISSN 0144-6193

Brusasco, P.L., Caneparo, L., Carrara, G., Fioravanti, A., Novembri, G. and Zorgno, A.M. 2000 Computer supported design studio. Automation in Construction, 9(4), pp. 393408. Elsevier Science

Burns, R. 2000 Introduction to Research Methods, 4th edn, Sage, London, pp. 566-94.

Caneparo, L. 2001 Shared virtual reality for design and management: the Porta Susa project. Automation in Construction, 10(2), pp.217-228. Elsevier Science

Checkland, P. 1981 Systems Thinking, Systems Practice, Wiley, Chichester

Cheng, E.W.L., Li, H., Love, P.E.D. and Irani, Z. 2001 An e-business model to support supply chain activities in construction. Logistics Information Management, 14(1/2). pp.6877. MCB University Press;

Chim, M.Y., Anumba, C.J. and Carrillo, P.M. 2004 Internet-based collaborative decision-making system for construction. Advances in Engineering Software, 25, pp.357371. Elsevier Science

Clemmet, A. 1997 The computer-supported cooperative work programme. Work Study, 46(2), pp.58-60. MCB University Press

Conner, M. and Finnemore, P. 2003 Living in the new age: using collaborative digital technology to deliver health care improvement. International Journal of Health Care Quality Assurance, 16(2), pp.77-86. Emerald, MCB University Press

Credé, A. 1997 Social, cultural, economic and legal barriers to the development of technology-based information systems, Industrial Management \& Data Systems, 97(1), pp.58-62. MCB University Press. ISSN 0263-5577

Donath, D., Loemaker, T.M. and Richter, K. 2004 Plausibility in the planning process reason and confidence in the computer-aided-design and planning of buildings. Automation in Construction. 13(2), pp.150-166. Elsevier Science

Dustdar, S. and Gall, H. 2003 Architectural concerns in distributed and mobile collaborative systems. Journal of Systems Architecture. 49, pp.457-473. Elsevier Science

Edenius, M. and Borgerson, J. 2003 To manage knowledge by intranet. Journal of Knowledge Management. 7(5), pp.124-136. MCB University Press. ISSN 1367-3270

Egan, J. 1998 Rethinking Construction, Report to the Construction Task Force on the scope for improving quality and efficiency of the UK construction industry, Dept. of Environment, Transport and Regions (DETR), London, UK

Egbu, C. 2004 Managing knowledge and intellectual capital for improved organisational innovations in the construction industry: an examination of critical success factors. 
Engineering, Construction \& Architectural Management. 11(5), pp.301-315. Emerald Group Publishing Limited. ISSN 0969-9988

Erdogan, B., Anumba, C.J., Bouchlaghem, N.M., and Nielsen, Y. 2005 Change

Management in Construction: The Current Context, Association of Researchers in

Construction Management (ARCOM 2005), Ed. by. Farzad Khosrawshahi, Vol 2 pp. 1085-

1095, London, UK, 7-9 September 2005

Eseryel, D., Ganesan, R. and Edmonds, G. 2002 Review of Computer-Supported Collaborative Work Systems. Educational Technology and Society, 5(2), 2002;

Faniran, O., Love, P.E.D., Treloar, G. and Anumba, C.J. 2001 Methodological issues in design-construction integration. Logistics Information Management, 14(5/6), pp.421-426. MCB University Press

Faraj, I., Alshawi, M., Aouad, G., Child, T. and Underwood, J. 2000 An industry foundation classes Web-based collaborative construction computer environment: WISPER. Automation in Construction. 10(1), pp.79-99. Elsevier Science

Ferneley E., Lima C., Fies B., Rezgui Y. and Wetherill M. 2003 Inter-organisational semantic webs to enable knowledge discovery and dissemination: technical support for the social process, Proceedings of the 10th ISPE International Conference on Concurrent Engineering (CE 2003), Madeira (Spain), pp. 779-785;

Fulton, C. 2002 Information control in the virtual office: preparing intermediaries to facilitate information exchange in the home work environment. New Library World. 103(1177), pp.209-215. Emerlad, MCB University Press, ISSN 0307-4803

Grudin, J. 1994 Computer-Supported cooperative work: its history and participation. IEEE Computer, 27(5), pp.19-26;

Hale, M.A. and Marvis, D.N. 2000 A lean-server foundation for collaborative design. Advances in Engineering Software. 31, pp.679-685. Elsevier Science Limited

Hew, K.P., Fisher, N. and Awbi, H.B. 2001 Towards an integrated set of design tools based on a common data format for building and services design. Automation in Construction. 10(4), pp.459-476. Elsevier Science

Hiremath, H.R. and Skibniewski, M.J. 2004 Object-oriented modelling of construction processes by unified modelling language. Automation in Construction. 13(4), pp.447-468, Elsevier Science.

Jasnoch, U. and Haas, S. 1996 A collaborative environment based on distributed objectoriented databases. Computers in Industry. 29, pp.51-61. Elsevier Science

Kidder, L. and Judd, C. 1986 Research Methods in Social Relations, CBS College Publishing/Holt, Rinehart and Winston

Koschmann, T., Kelson, A.C., Feltovich, P.J. and Barrows, H.S. 1996 Computersupported problem based learning: a principled approach to the use of computers in collaborative learning. In T. Koschmann (Ed.), CSCL: Theory and Practice (pp.83-124). Mahwah, NJ: Lawrence Erlbaum Associates;

Koseoglu, O.O., Erdogan, B., Nielsen, Y., Anumba, C.J. and Bouchlaghem, N.M. 2005 Visual Information Transfer using Mobile IT Solutions, Proceedings of the Tenth International Conference on Civil, Structural and Environmental Engineering Computing, Topping, B.H.V.(Editor), Civil-Comp Press, Stirling, Scotland, 29-30

Kundu, S.C. 2004 Impact of computer disasters on information management: a study. Industrial Management \& Data Systems. 104(2),

Kunz, J. 1999 AEC 2000-2025: visions, opportunities and issues, Berkeley-Stanford CE\&M Workshop, Stanford.

Kusiak, A. and Wang, J. 1993 Decomposition of the Design Process. Journal of Mechanical Design, 115, pp. 687-695;

Kvan, T. 2000 Collaborative Design: what is it? Automation in Construction, 9(4), pp.409415; 
Latham, Sir M. 1994 Constructing the Team, Final report of the Government/Industry review of procurement and contractual arrangements in the UK construction industry, HMSO, London

Lau, H.Y.K., Mak, K.L. and Lu, M.T.H. 2003 A virtual design platform for interactive product design and visualisation. Journal of Materials Processing Technology. 139, pp.402407. Elsevier Science

Li, W.D., Fuh, Y.J.H. and Wong, Y.S. 2004 An internet-enabled integrated system for codesign and concurrent engineering. Computers in Industry. 55, pp.87-103. Elsevier Science Li, Y., Shao, X., Li, P. and Liu, Q. 2004 Design and implementation of a process-oriented intelligent collaborative product design system. Computers in Industry, 53, pp.205-229. Elsevier Science

Loosemore, M. 1998 Organisational behaviour during a construction crisis. International Journal of Project Management. 16(2), pp.115-121. Elsevier Science.

Lueg, C. 2001 Information, knowledge, and networked minds. Journal of Knowledge Management. (5)2, pp.151-159. MCB University Press, ISSN 1367-3270

Maguire, S. 2002 Identifying risks during information system development: managing the process. Information Management \& Computer Society. 10(3), pp.126-134. Emerald, MCB University Press

Manthou, V., Vlachopoulou, and Folinas, D. 2004 Virtual e-Chain (VeC) model for supply chain collaboration. International Journal of Production Economics. 87, pp.241-250. Elsevier Science Limited;

May, A. and Carter, C. 2001 A case study of virtual team working in the European automotive industry. International Journal of Industrial Ergonomics. 27, pp.171-186. Elsevier Sceince

McFadzean, E. and McKenzie, J. 2001 Facilitating virtual learning groups - a practical approach. Journal of Management Development, 20(6), pp.470-494. MCB University Press Moore, C.J. 2000 Collaborative and concurrent engineering in the construction industry. Artificial Intelligence in Engineering, 14,pp. 201-202. Elsevier Science

Newell, R. 1993 'Questionnaires', in N. Gilbert (ed.), Researching Social Life, Sage, London, pp. 94-116

Nitithamyong, P. and Skibniewski, M.J. 2004 Web-based construction project management systems: how to make them successful? Automation in Construction. 13(4), pp.491-506. Elsevier Science

Norton, D.P. 1995 Managing benefits from information technology. Information Management \& Computer Society. 3(5), pp.29-35. MCB University Press Limited Peña-Mora, F., Hussein, S., Vadhavkar, S. and Benjamin, K. 2000 CAIRO: a concurrent engineering meeting environment for virtual design teams. Artificial Intelligence in Engineering. 14, pp.203-219. Elsevier Science

Proctor, S. and Brown, A.D. 1997 Computer-integrated operations: the introduction of a hospital information support system. International Journal of Operations \& Production Management. 17(8), pp.746-756. MCB University Press

Rezgui, Y., Brown, A., Cooper, G., Yip, J., Brandon, P. and Kirkham, J. 1996 An information management model for concurrent construction engineering. Automation in Construction, 5(4), pp.343-355, Elsevier Science

Robertson, S. and Robertson, L. 1999 Mastering the Requirements Process. Addison Wesley. ISBN 0-201-36046-2

Robillard, P.N. and Robillard, M.P. 2000 Types of collaborative work in software engineering. The Journal of Systems and Software, 53, pp.219-224. Elsevier Science Schwegler, B. 1999 4D tools research needs punch list, Berkeley-Stanford CE\&M Workshop, Stanford.

Sexton, M. and Barrett, P. 2004 The role of technology transfer in innovation within small construction firms. Engineering, Construction and Architectural Management. 11(5), pp.342-348. Emerald Group Publishing Limited, ISSN 0969-9988 
Shelbourn, M., Bouchlaghem, D., Koseoglu, O.O., and Erdogan, B. 2005 Collaborative Working and its effect on the AEC organisation. Proceedings of the International Conference on Computing in Civil Engineering, Cancun, Mexico, July $11^{\text {th }}-15^{\text {th }}$.

Smoliar, S.W. 2003 Interaction Management - the next (and necessary) step beyond knowledge management. Business Process Management. 9(3), pp.337-353. Emerald, MCB University Press Limited.

Sriprasert, E. and Dawood, N. 2003 Multi-constraint information management and visualisation for collaborative planning and control in construction. ITcon, 8, pp.341-366. Available from: http://www.itcon.org. Last visited $26^{\text {th }}$ January 2005

Stewart, R.A., Mohamed, S. and Daet, R. 2002 Strategic implementation of IT/IS projects in construction: a case study. Automation in Construction. 11(6), pp.681-694, Elsevier;

Stewart, R.A. and Mohamed, S. 2003 Evaluating the value IT adds to the process of project information management in construction. Automation in Construction. 12(4), pp.407-417. Elsevier Science

Tiwna, A. 2000 The Knowledge Management Toolkit, Prentice Hall.

Vakola, M., and Wilson, I.E. 2002 The Challenge of Virtual Organisation: Critical success factors in dealing with constant change, Proceedings of the European Conference on Information and Communication Technology Advances and Innovation in the Knowledge Society (eSM@RT 2002 in Collaboration with CISEMIC 2002), Rezgui Y., Ingirige B., Aouad G. (ed.), Salford (UK), 18-21 November, Part B, pp. 264-275

van Leeuwen, J.P. 2003 Computer support for collaborative work in the construction industry. In cha, Gonçalves and Steiger-Garção, Proceedings of the International Conference on Concurrent Engineering, Maderia, Portugal, July 26-30, 2003, Balkema Publishers, pp.599-606

Waly, A.F. and Thabet, W.Y. 2002 A virtual construction environment for preconstruction planning. Automation in Construction. 12(2), pp.139-154, Elsevier Science

Wang, L., Shen., Xie, H., Neelamkavil, J. and Pardasani, A. 2002 Collaborative conceptual design - state of the art and future trends. Computer-Aided Design. 34, pp.981996. Elsevier Science

Weippert, A., Kajewski, S.L. and Tilley, P.A. 2003 The implementation of online information and communication technology (ICT) on remote construction projects. Logistics Information Management. 16(5), pp.327-340. Emerald, MCB University Press

Whyte, J. 2003 Industrial applications of virtual realityin architecture and construction. ITcon, 8, pp.43-50. Available from: http://www.itcon.org. Last visited $26^{\text {th }}$ January 2005

Wilkinson, P. 2005 Construction Collaboration Technologies. Spon Press. ISBN: 0415358590

Willaert, S.S.A., de Graaf, R. and Minderhoud, S. 1998 Collaborative engineering: a case study of concurrent engineering in a wider context. Journal of Engineering and Technology Management (JET-M), 15, pp.87-109. Elsevier Science

Winograd, T. 1998 A Language/Action Approach on the design of cooperative work. Human Computer Interaction, 3(1), pp.3-30;

Woo, S., Lee, E. and Sasada T. 2001 The Multiuser workspace as the medium for communications in collaborative design. Automation in Construction, 10(3), pp.303-308, Elsevier Science;

Zhu, Y. and Issa, R.A.R. 2003 Viewer controllable visualisation for construction document processing. Automation in Construction. 12(3), pp.255-269. Elsevier Science 